\title{
Editorial: Progress in energy demand reduction - from here to 2050
}

Geoffrey P. Hammond

Professor of Mechanical Engineering, University of Bath, Bath, UK

Energy systems pervade industrial societies and weave a complex web of interactions that affect the daily lives of their citizens. Such societies face increasing pressures associated with the need for a rapid transition towards a low carbon dioxide and secure energy future at moderate cost (that is, one which is affordable or competitive). These three elements represent the so-called energy policy 'trilemma' (Hammond and Pearson, 2013). In terms of the first element, the British government established a legally binding target of reducing the nation's carbon dioxide emissions overall by $80 \%$ by 2050 in comparison to a 1990 baseline (Climate Change Act 2008, 2008; DTI, 2007). That will be a very difficult task to achieve. Thus, the three elements of the 'trilemma' collectively present many challenges that will require a portfolio of energy options to surmount them: energy demand reduction and efficiency improvements, carbon dioxide capture and storage (CCS) from fossil fuel power plants and a switch to low or zero carbon dioxide energy sources (such as combined heat and power (CHP), nuclear power stations and renewable energy technologies on a large and small scale). The demand for energy, however, is the main driver of the whole energy system. It gives rise to the total amount of energy used, as well as the location, type of fuel and characteristics of specific end-use technologies. Consequently, the need for reductions in energy demand, and associated 'greenhouse gas' (GHG) emissions, applies across the end-use spectrum from the built environment to industrial processes and products, from materials to design, and from markets and regulation to individual and organisational behaviour. In order to analyse rigorously the energy and environmental consequences of changes in supply and demand of energy-intensive goods and services, it is necessary to take a holistic perspective (Hammond, 2000). This implies drawing the system boundary quite widely - across the "whole energy system' or 'fuel chain' on a life-cycle basis. Such an approach is needed because of the complex interaction between sectors and their impacts during the transition to a 'low carbon' future. It is therefore important to trace the whole life of products, services and supporting infrastructure, and their associated energy flows and pollutant emissions, as they pass through the economy. A simplified model of energy flows in the UK is illustrated in Figure 1 (Hammond, 2000). It should be noted that heat is potentially wasted and energy is 'lost' at each stage of energy conversion, transmission and distribution, particularly in connection with the process of electricity generation. This schematic energy flow diagram hides many feedback loops in which primary energy sources (including fossil fuels, uranium ore and hydro-electric sites) and secondary derivatives (such as hydrogen fuel or nuclear- and renewable-generated electricity) provide upstream energy inputs into the 'energy transformation system' (Slesser, 1978). The latter is that part of the economy where a raw energy resource is converted into useful energy which can meet downstream, 'final' or 'end-use' demand. 'Renewable' energy sources are taken to mean those that are ultimately solar-derived: mainly solar energy itself, biomass resources and wind power (Hammond, 2000).

Reducing the use of energy can be encouraged in various ways. Energy efficiency improvements result from using less energy for the same level of output or service, where the output can be measured in terms of either physical or economic units (i.e. tonnes or pounds sterling). But consumers can also be encouraged to reduce their energy use by changing their service demands. One obvious way of doing that is by way of the adoption of a lower comfort temperature in the home or at the workplace, thereby requiring less energy to deliver it. Human behavioural changes of this type can be aided by the introduction of regulatory interventions (e.g. on boilers), fiscal measures (like those associated with the UK government's recent 'Green Deal' programme (see Rosenow and Eyre, 2013)), or by devices such as 'smart' meters or appliances (Post, 2012). The latter technologies can play an important part in securing demand-side response (DSR) that better matches enduse electricity demand with supply (Pudjianto et al., 2013). Energy demands on the electricity network vary throughout the day, with peaks typically in the morning and evening. This profile may be smoothed, and the overall power requirement lowered, by shifting energy demands from household appliances (such as those for refrigerators, storage heaters, or washing machines) to other periods of the day. Flexible tasks in industry and the commercial sector can likewise be shifted to off-peak times. Thus, this themed issue of Energy focuses principally on two key elements: (a) changing end-use technologies at the point of energy demand in the built environment, transport and industry; and (b) lifestyle and 
Editorial: Progress in energy

demand reduction - from here

to $\mathbf{2 0 5 0}$

Hammond social drivers of the demand for energy services, including the institutional and policy frameworks within which technical and social decisions are made. The use of information and communications technology (ICT) increases the operability, control and visibility of the various demand reduction options. The papers that make up the themed issue emanate from research funded by various components of the Research Councils UK (RCUK) Energy Programme.

The scope for energy demand and GHG emissions reduction, or the improvement in resource use efficiency more broadly, can be viewed in the context of 'sustainability'. A representation of the 'three pillars' of sustainable development balancing economic and social development with environmental protection - can be obtained using the so-called 'IPAT' equation devised by Holdren and Ehrlich (1974) for analysing environmental disruption

1.

(Environmental) impact $=$ population $\times$ affluence $\times$ technology

This expression has more recently been termed the 'sustainability equation' by Jacobs (1996). Affluence, or economic consumption per person, is normally measured by gross domestic product (GDP) per capita. GDP is the traditional measure of wealth creation adopted by economists at the level of the nation state: the total output of goods and services in money terms produced within a national economy. In the period since the early 1960 s this has tended to increase over time in the wealthy countries of the industrialised world (those of the so-called 'North' of the planet), while typically falling in the poorer or less developed nations (of the 'South'). The situation with demographic growth has been quite different, for example, with almost stable populations in many affluent countries of Northern Europe. In contrast, rapid population growth has been observed in many parts of the developing world; Africa, continental Asia, and Central and South America. The 'technology' component in Equation 1 represents the environmental damage per unit of consumption. According to Meadows et al. (1992) the scope for reducing the various terms on the right-hand side of the IPAT equation is very large over a $50-100$ year timescale. Table 1 is adapted from this work, although Meadows et al. attribute the estimates of the potential for long-term change and the associated timescales to Amory Lovins (in a paper that the present author (Hammond, 2004) has been unable to locate, even from the originators (i.e. by way of correspondence with the lead author and pioneering American environmental scientist: the late Dr Donella H. 'Dana' Meadows, 1941-2001)). Obviously the individual columns in this table reflect global aggregate figures or averages. Each socioeconomic region or nation-state would need to place a different emphasis on which component of the sustainability equation they tackled. The focus in the industrialised world, where the population is stable, would have to be principally on resource productivity (the 'technology' element). In developing countries with rapidly growing populations, both population and resource productivity changes will be required in order to secure sustainable development. There may also need to be a more equitable sharing of wealth in the long-run (Hammond, 2004). This implies some convergence in GDP per capita between developed and developing countries; a task that is

\begin{tabular}{|c|c|c|c|c|}
\hline \multirow{3}{*}{$\begin{array}{l}\text { Population } \\
\text { Population }\end{array}$} & \multicolumn{2}{|c|}{ Affluence } & \multicolumn{2}{|c|}{ Technology } \\
\hline & Capital stock & Material throughput & Energy & Environmental impact \\
\hline & Person & Capital stock & $\times \overline{\text { Material throughput }}$ & Energy \\
\hline \multicolumn{5}{|l|}{ Applicable tools } \\
\hline Family planning & Values & Product longevity & End-use efficiency & Benign sources \\
\hline Female literacy & Prices & Material choice & Conversion efficiency & Scale \\
\hline Social welfare & Full costing & Minimum materials design & Distribution efficiency & Siting \\
\hline Role of women & What do we want? & Recycle, reuse & System integration & Technical mitigation \\
\hline Land tenure & What is enough? & Scrap recovery & Process redesign & Offsets \\
\hline \multicolumn{5}{|c|}{ Approximate scope for long-term change } \\
\hline$\sim 2 \times$ & $?$ & $\sim 3-10 \times$ & $\sim 5-10 \times$ & $\sim 10^{2}-10^{3+} \times$ \\
\hline \multicolumn{5}{|c|}{ Time scale of major change } \\
\hline$\sim 50-100$ years & $\sim 0-50$ years & $\sim 0-20$ years & $\sim 0-30$ years & $\sim 0-50$ years \\
\hline
\end{tabular}

Source: Hammond (2004); adapted from Meadows et al. (1992) and based on the original estimates made by Amory Lovins.

Table 1. The environmental impact of population, affluence and technology 


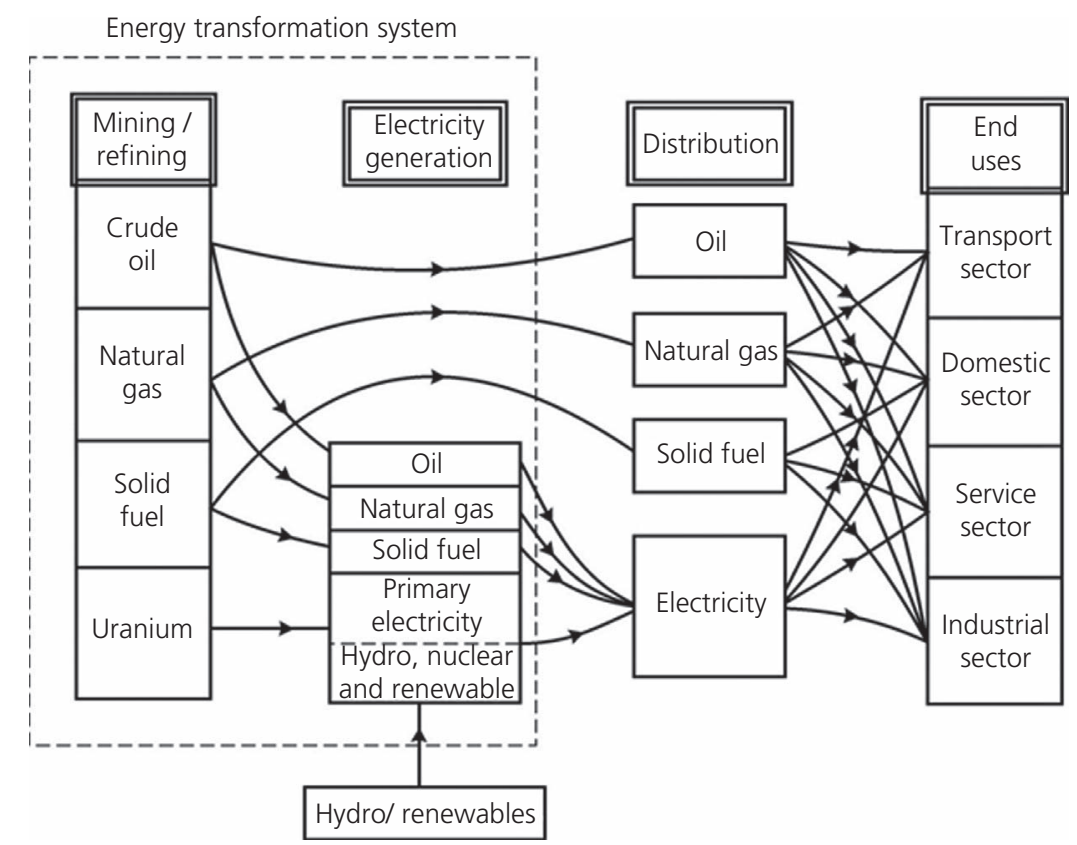

Figure 1. A simplified representation of the UK energy system

(source: Hammond, 2000)

obviously fraught with political difficulties. Nevertheless, the multiplier effect of the IPAT equation suggests that significant reductions in environmental impact (by way of falls in the rate of population growth or increases in resource productivity, like those indicated in Table 1) are possible overall.

There is obviously a need to stimulate improvements in resource use efficiency generally, and to encourage energy demand reduction from the 'bottom up'; induced by way of a portfolio of measures to counter market deficiencies economic instruments, environmental regulation and land use planning procedures. Scenarios such as the 'dematerialisation' or 'Factor Four' project advocated by Ernst von Weizsacker and Amory and Hunter Lovins (von Weizsacker et al., 1997) suggest that economic welfare in the industrial world might be doubled while resource use is halved; thus the 'Factor 4'. This would involve a structural shift from energy-intensive manufacturing to energy-frugal services (Herring, 1999). Britain has moved some way in this direction, with a $40 \%$ improvement in primary energy intensity since 1965 (Hammond, 2000). Increases in resource use efficiency at the 'Factor 4' level (von Weizsacker et al. (2009) subsequently advocated 'Factor 5' increases (or an $80 \%$ improvement in resource productivity) and the UK Foresight Programme even contemplated 'Factor 10 ' over the long-term) would have an enormous knock-on benefit of reducing pollutant emissions that have an impact, actual or potential, on environmental quality. Improvements in resource efficiency of this type have been advocated in the UK by Allwood and Cullen (2011), albeit with a focus on material use. In reality, such a strategy requires a major change ('paradigm shift') to an energy system that is focused on maximising the full fuel/energy cycle efficiency, and minimising the embodied energy in materials and products by way of reuse and recycling (Hammond and Jones, 2008, 2011). In order to make such an approach a practicable engineering option, it would be necessary to use systems analysis methods to optimise the energy cascade. Thermodynamic analysis will be an important technique for identifying process improvement potential (Hammond, 2000, 2004).

This themed issue of Energy addresses challenges related to energy demand and reduction of GHG emissions in each of the end-use sectors identified in Figure 1. A multidisciplinary team of UK engineers, social scientists, policy analysts and innovation specialists has recently sought to develop and explore three 'transition pathways' towards a UK low carbon electricity system in 2050 (Foxon et al., 2010; Hammond and Pearson, 2013). These pathways provide a basis for framing the potential contribution of energy demand reduction measures (see Figures 2-4 (Barton et al., 2013a)). The starting point in the development of these UK transition pathways, unlike many scenario-building exercises, was the governance framings or 'logics' of key actors will be a crucial influence on any pathway towards a future low carbon UK energy system. This was followed by 'whole systems' analysis of the pathways in terms of their technical, socio-economic and environmental implications. 
Energy

Volume 167 Issue EN3
Editorial: Progress in energy

demand reduction - from here

to $\mathbf{2 0 5 0}$

Hammond

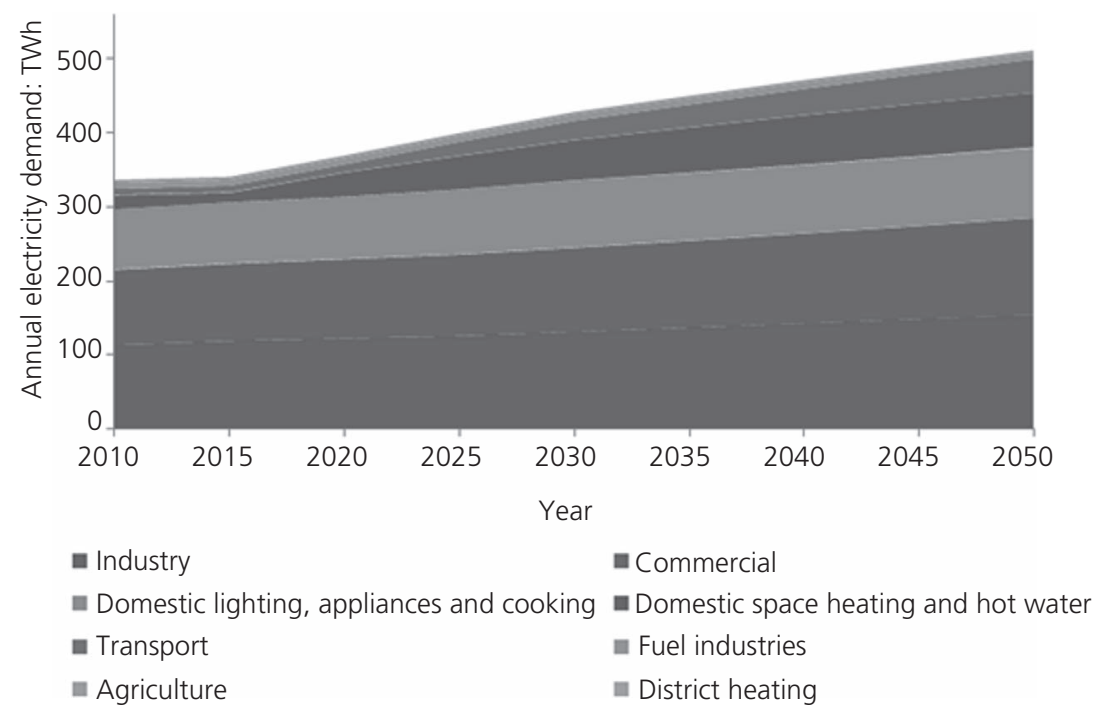

Figure 2. Annual electricity demand (TWh) under the UK 'market rules' (MR) transition pathway (version 2.1): 2010-2050 (source: adapted from Barton et al. (2013a); based on Barton et al. (2013b))

Stakeholder workshops were employed by the consortium to distinguish the logics of three core sets of actors (Hammond and Pearson, 2013): those of the market, government and civil society. Consequently, the three transition pathways were named 'market rules' (MR), 'central co-ordination' (CC) and 'thousand flowers' (TF) respectively; each being dominated by a single group's logic (Foxon et al., 2010; Hammond and Pearson, 2013). This schema builds on approaches originally devised by Dutch researchers (e.g. Geels, 2002; Rip and Kemp, 1998). Thus, the consortium applied a multi-level perspective for

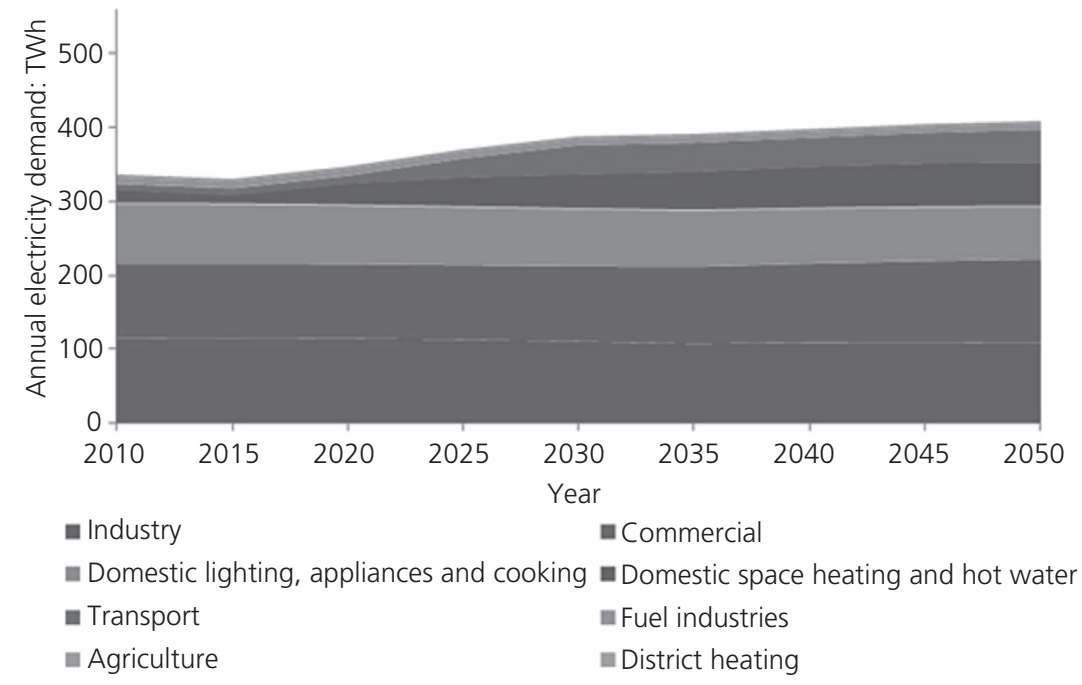

Figure 3. Annual electricity demand (TWh) under the UK 'central co-ordination' (CC) transition pathway (version 2.1): 2010-2050 (source: adapted from Barton et al. (2013a); based on Barton et al. (2013b)) 


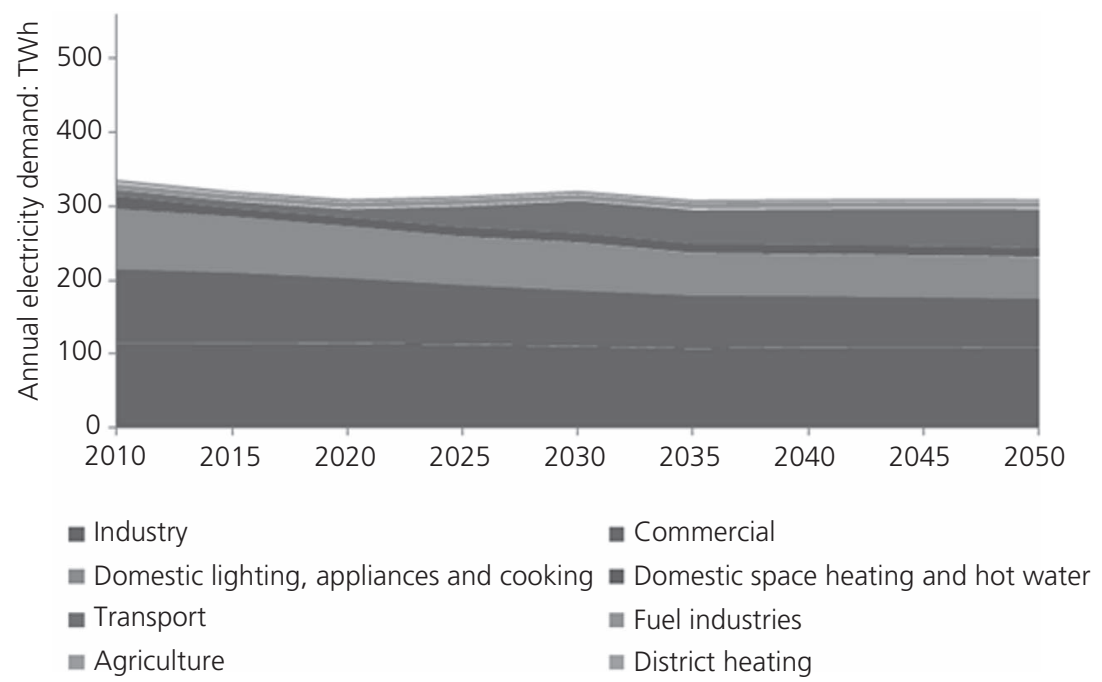

Figure 4. Annual electricity demand (TWh) under the UK 'thousand flowers' (TF) transition pathway (version 2.1): 2010-2050 (source: adapted from Barton et al. (2013a); based on Barton et al. (2013b))

analysing socio-technical transitions, based on interactions at and between three levels: niche innovations, socio-technical regimes and macro-landscape pressures (Foxon et al., 2010). The pathways are not predictions or roadmaps; rather they are a way of imaginatively exploring future possibilities, to inform proactive and protective decision making and enhance the potential for building consensus towards common goals (Hammond and Pearson, 2013). The projections (see Barton et al. (2013b), who were part of the consortium) suggest continued growth in absolute levels of electricity use under the MR pathway (Figure 2), despite continued technical improvements in appliances and building fabric. However, this reduction comes at a price, with significant 'excess' generation locally at times of low electricity demand, as CHP follows heat demands, exacerbating the problem of low-capacity factors for central generation caused by growth in the role of intermittent renewables. A variety of 'demand side participation' (DSP) measures have been modelled (Barton et al., 2013b) in order to determine whether this conventional generation can be minimised. DSP is found to yield significant benefits in this regard. Load shifting, for example, is shown to address this problem effectively, but would require widespread acceptance of the automatic control of appliances and/or 'deep' behavioural changes (Post, 2012).

The UK building stock is estimated to consist of some $25 \cdot 5$ million domestic buildings, together with 1.98 million nondomestic buildings (Brown et al., 2009). Energy demand from the building to city scales then arises from a multiplicity of factors: services (e.g. cooking, lighting, space and water heating, etc.), the building fabric, end-use devices, local energy conversion/storage and social practices (e.g. behaviours and lifestyles). There is potential for emissions mitigation in all of these facets, and many opportunities exist to reduce the energy needed to satisfy basic energy services in existing and new build stock over the transition period towards a low carbon future by 2050. Issues concerned with the domestic sector of the UK economy are therefore considered in the first two papers of this themed issue: by Pelenur and Cruickshank (2014) and by Killip et al. (2014) respectively. The transition pathways projections suggest a significant fall in final demand in the domestic sector from $\sim 500 \mathrm{TWh}$ pa under the MR pathway (Figure 2) to only $\sim 310 \mathrm{TWh}$ pa under its TF counterpart by 2050 (Figure 4). The CC pathway (Figure 3) can be seen to be intermediate between these trajectories (at $\sim 400 \mathrm{TWh}$ pa by 2050). Pelenur and Cruickshank (2014) link demographic variables with motivations for the adoption of domestic energy efficiency measures within UK cities, based on an Engineering and Physical Sciences Research Council (EPSRC) funded research project entitled 'Re-engineering the city 2020-2050 (Retrofit 2050) - Urban foresight and transition management'. These demographic variables were statistically connected to the identified motivations using a modified chi-square test of association (by way of a first-order Rao-Scott correction to compensate for multiple response data), and the effect size was estimated with an 'odds-ratio' test. It draws on data collected from 149 'general population' interviews (of 1·5-10 min each) carried out across multiple locations in Manchester and 
Editorial: Progress in energy

demand reduction - from here

to $\mathbf{2 0 5 0}$

Hammond
Cardiff. These results, together with findings from their earlier study (Pelenur and Cruickshank, 2012), lead to recommendations that are aimed at policy makers, local councils and members of the construction/retrofit industry. They argued that single individuals currently earning less than $£ 40000$ a year and living in apartments/flats are motivated to save resources and be more efficient out of general principle (related to environmental protection), although such householders cited their landlord-tenant/housing association as the main barrier preventing their adoption of energy efficiency measures. In contrast, Pelenur and Cruickshank (2014) suggest that married/common-law individuals with incomes greater than $£ 40000$ a year and living in semi/detached homes were motivated primarily to save money. However, these respondents reported that their physical property was the significant barrier preventing their adoption of energy efficiency measures, either due to planning permission, age of home, space constraints, heritage, or such like. Pelenur and Cruickshank (2014) therefore contend that the uptake of schemes such as the Green Deal (see again Rosenow and Eyre, 2013) might be increased by targeting households that match the first category of single individuals with the correct message; that is, reducing waste and increasing efficiency. The Green Deal attempts to address the constraint caused by the fact that landlords bear the cost of energy efficiency improvements, while it is the tenant who receives the financial benefit of reduced energy bills. It also seeks to introduce greater use of private (nonenergy sector) finance into low carbon building refurbishment (Rosenow and Eyre, 2013). Clearly, reforms of this type should be promoted to households that match the second profile of occupants (Pelenur and Cruickshank, 2014) with a cost saving message in order to ensure the effectiveness of the scheme. However, Rosenow and Eyre (2013) argue that the relatively modest ambitions of the Green Deal programme are unlikely to be met. This is because the supply chain may be unable to deliver the scale of improvements required on the defined time frame, and the scheme itself does not address the many nonfinancial barriers to the take-up of energy efficiency improvements that have been identified in the literature.

In the second paper related to the domestic sector (Figure 1), Killip et al. (2014) seek to explore the challenges and opportunities for low-energy renovation within the residential sector of both France and the UK. They describe the policy environment for renovation in each country, and show how it influences organisations undertaking refurbishment. This work has been jointly supported by the EdF European Centre and Laboratories for Energy Efficiency Research (Ecleer) and the RCUK Energy Programme under its 'People, energy, and buildings' theme. The main parameter that determines the increase in domestic energy use is the rise in the number of dwellings. Population in the UK, for example, has risen only slowly over the last few decades (Brown et al., 2009) and, correspondingly, the number of households and residential energy use has increased at a similar rate over the period since 1970. At any given time, the bulk of the domestic housing stock will be made up of existing buildings, and hence the need for renovation in order to facilitate energy demand reduction. British and French case studies are used to identify the common challenges of low-energy refurbishment, potential responses by innovative construction firms, and lessons on practices and processes that could be useful to the wider industry. The UK case concerns a social housing organisation, which has developed innovative ways of working and delivering high-quality results at lower than expected costs. In contrast, the French case profiles a new start-up company with a co-operative governance structure offering guaranteed performance contracts to clients for its renovation services. Killip et al. (2014) adopt the idea of a 'soft landings' approach to building handover that is often employed in the commercial sector in order to interpret their multi-national case studies and frame their analysis of the sector. Here designers and constructors/renovators stay engaged with buildings beyond the initial practical completion to assist the client during the first months of operation and beyond. During this initial period, they consequently help in fine-tuning systems so that the occupiers understand how to make best use of their buildings; thereby ensuring a 'soft landing'. Nevertheless, Killip et al. recognise that the residential sector is rather different in character to the commercial one. They go on to identify a number of common themes for innovative firms from their case studies: the possibility of new configurations of traditional roles and responsibilities on-site (for the architect, engineer, builder, electrician, etc.); they examine whether new ways of responding to the requirements and behaviours of building occupants may be developed; and they suggest the need for an integration of different feedback mechanisms to provide learning from project to project. If low-energy renovation is to move beyond its current 'niche', then Killip et al. (2014) contend that the management of different types of interfaces needs to be achieved on building sites both large and small. In the housing sector, this raises the issue of whether engineers, for example, should play a more active role in smaller projects.

The internal combustion (IC) engine-driven car has dominated road transport for more than 100 years (Hammond and Pearson, 2013). This technological lock-in comes partially from the production side, where it has not been regarded as being economically attractive to invest in new automotive power trains that appear non-competitive in cost terms. Many large, multi-national car manufacturers struggling to survive (Dijk et al., 2013) have found it both more attractive and safer to invest in innovation associated with existing IC engine technology than in technological options that carry a potential risk of low consumer acceptance. This yields a pattern in which 
Editorial: Progress in energy

demand reduction - from here

to 2050

Hammond car manufacturers continuously refine the dominant design in order to improve environmental performance of IC engines (Dijk and Yarime, 2010), rather than making a 'great leap forward'. Thus, the development of hybrid technology can be seen as an attempt by car assemblers to innovate without having to move away from their core competencies. The agenda for low-energy design concepts in road vehicles has arguably been set by Amory Lovins with his vision of a 'hypercar' in the 1990s (see, for example, Hammond, 2000; von Weizsacker et al., 1997). This vehicle, termed 'supercar' in the original report, was postulated as being able to leapfrog incremental design improvements by adopting next-generation technologies from other advanced industries. Thus, the hypercar would have an ultra-light, aerodynamically shaped body fabricated using composite materials. It could utilise a hybrid power train in the form of a small (petrol or perhaps diesel) engine that would power electric motors at the wheels. In fact, 'lightweighting' is the key to energy and emissions reduction in road vehicles (see, e.g. Allwood and Cullen, 2011; Dyer et al., 2008). Lovins argued that such a combination might lead to fuel efficiencies of up to 360 mile/gallon $(153 \mathrm{~km} / \mathrm{l})$ but with the performance of top BMWs. This hypercar concept has been influential outside the USA. In the UK it stimulated the Transport Foresight Panel (Technology Foresight, 1995) to advocate the development of a 'Foresight vehicle' that is significantly more environmentally friendly than current designs, but which meets mass market expectations in terms of cost, performance and safety. The Panel suggested that a range of motor car power systems could be encompassed within the development programme, including clean fuel IC engines, as well as electric and hybrid drives (collectively termed 'low-emission vehicles'). A 'Foresight vehicle' programme was subsequently funded by the UK government initially over the period 1997-2005.

On the road transport infrastructure side, the 'refuelling' subsystem necessitates storage at the filling station and the refuelling process itself. Here liquid biofuels hold out the prospect of retaining the existing transport infrastructure (e.g. refuelling or 'petrol' stations), in contrast to other low carbon options, such as electric vehicles (EVs) and hydrogen-fuelled vehicles (Hammond and Pearson, 2013). However, the last 5 years (i.e. 2005-2010) has seen a greater period of innovation in electric mobility (Dijk et al., 2013), which has arguably crossed a critical threshold and is now benefitting from various developments whose influence can be expected to grow in importance: high oil prices, carbon dioxide constraints and the rise of organised car sharing and inter-modality. Dijk et al. (2013) therefore suggest that technological alternatives, including future synergies between battery plug-in vehicles (PiV), hybrid electric and hydrogen fuel cell vehicles, are likely to be important drivers for the future evolution of the interlinked energy and transport sectors out to 2050 and beyond. Indeed Morton et al. (2014) suggest that EVs offer a possible means by which the transport sector can partially address the objectives of decreasing emissions of carbon dioxide, while improving both energy efficiency and energy security (part of what might be termed a policy 'trilemma' for road transport). They examine the potential barriers which may be suppressing demand for EVs and the uncertainties concerning their take-up by way of a conceptual framework developed from that originally proposed by Walker et al. (2003) and updated according to Meijer et al. (2006). Thus, the focus is on six different 'locations' of uncertainty covering the consumer, technical, economic, social, infrastructure and policy domains. This research has been supported by way of the UK Energy Research Centre (UKERC) energy demand theme as part of the 'Energy strategy under uncertainty' project. UK government and European Union (EU) Commission policy documents have been evaluated by Morton et al. in order to determine the extent to which policy makers have so far made efforts to reduce the uncertainties associated with EV demand. In this context, environmental uncertainty is implicitly incorporated within the framework as a cross-cutting theme by way of the technical, social and political (or policy) domains. Morton et al. (2014) note that criticisms have been levelled at UK and EU authorities for a lack of ambition, as well as ineffective integration and collaboration across various departments ('energy', 'planning' and 'transport', for example). They also suggest that these governmental bodies tend to take a simplistic approach to 'consumer dynamics' when undertaking policy development. Nevertheless, they recognise that various other policies have been effective when applied to the EV market, for example, the widespread adoption of ecolabels, clear messaging in terms of manufacturer targets for average vehicle carbon dioxide emissions and significant financial commitments to the support of developments in this emerging marketplace.

Electrification of heating sectors and transport (EHT) fleets are both recognised as being key strategies to further reduce the use of fossil fuels and the resulting GHG emissions (see Figures 2-4 (Barton et al., 2013a)). The intermittency and inflexibility of low carbon generation, however, mean that fossil-fuelled generation must be replaced to a greater extent than suggested by annual average figures, if required carbon dioxide reductions are to be achieved. The EV market, in particular, may lead to a rapid growth that could bring significant changes to power system demand patterns and operation (Hammond and Pearson, 2013). Thus, the UK transition pathways postulate increased electrification of transport and heating (see again Figures 2-4), which could result in greater peak demands on the network (by 2-3 times up to 2050 (Pudjianto et al., 2013)) that would be disproportionally higher than the increase in energy consumption. The MR pathway, for example, sees continued growth in absolute levels of electricity use, despite continued technical improvements in appliances and building fabric; peak demands also grow, to some $83 \mathrm{GW}$ by 2050 (Barton et al., 2013b). 
Editorial: Progress in energy

demand reduction - from here

to $\mathbf{2 0 5 0}$

Hammond
Enhanced energy demand reduction measures contribute to lower trends in the $\mathrm{CC}$ and TF pathways, and greater use of non-electricity sources for heating, notably CHP. Demand is driven down further in TF, such that peak demand is only $38 \mathrm{GW}$. But this fall leads to significant 'excess' generation locally at times of low electricity demand, as CHP follows heat demands, exacerbating the problem of low-capacity factors for central generation caused by growth in the role of intermittent renewables. Significant generation, transmission and distribution network reinforcements (operating with much lower utilisation factors) will therefore be needed, including tens of billions of pounds of distribution network investment. Baruah et al. (2014) employ a 'systems of systems' modelling framework, and the soft linking of models, input assumptions and data sources, in order to address a number of issues arising from a potential high electrification future for Great Britain. This suite of explicit energy demand and supply models was developed within the EPSRC UK Infrastructure Transitions Research Consortium (Hall et al., 2013), and has been used to analyse a high heat and transport electrification scenario that could reduce overall annual energy consumption, while considerably increasing both annual electricity consumption and peak load. This is shown to increase electricity consumption by $93 \%$ and its peak load by $35 \%$ compared to their reference scenario. Baruah et al. estimated transport energy from the projected transport services demand obtained using scenario-specific vehicle fuel efficiency levels extracted from the UK transport carbon dioxide model (UKTCM) of Brand et al. (2012); devised by two of the co-authors of the paper by Morton et al. (2014).

The greater use of DSP measures available with electrification, such as 'vehicle-to-grid' (V2G) technologies, may make it possible to limit or even reduce the peak loads below the reference scenario levels of Baruah et al. (2014). But they observe that, without peak demand management, electricity generation capacity and transmission costs in their 'high electrification' scenario could vary widely depending on the supply mix adopted. This was found by Baruah et al. to range from $\sim £ 450$ to $£ 1100$ billion for what they regarded as two highly plausible supply mixes. One favoured mitigation strategy is to utilise domestic offshore wind resources to meet the high electricity demand, although Baruah et al. (2014) found that this would mean high infrastructure costs and continued dependence on significant natural-gas-fired back-up capacity for maintaining grid flexibility. Electrification could also reduce UK dependence on imported gas and oil, while enabling connection of a large part of the electricity system to a future European supergrid and the energy market. However, Bolton and Foxon (2011) recently charted the 'co-evolution' between technologies and institutions in electricity networks since the introduction of privatisation and market liberalisation over 20 years ago. They observed that efforts to promote radical and 'architectural' innovation, such as the transition to a smart grid, face significant barriers at the firm and sector levels.

Pudjianto et al. (2013) argued that massive distribution network reinforcement would be required to support an electrification (EHT) scenario. They estimated cumulative electricity network reinforcement costs of up to $£ 36$ billion over the period 2010 2050 for a peak load of $\sim 3$ times the base year level. However, this is less than $\sim 3 \%$ of capacity and transmission costs in the EHT-offshore scenario of Baruah et al. (2014), where the peak load was estimated to be $2 \cdot 7$ times the base year level. They addressed the benefits of various applications of 'smart' network control and demand response technologies for enhancing the integration of future load categories, and for improvements in operation management and efficient use of distribution network assets. Likewise, Pudjianto et al. (2013) have argued that a coordinated application of smart demand technologies, such as smart EV charging, smart heat pump control and active distribution networks with the use of voltage regulators, may significantly reduce such network reinforcement costs. They employed a range of numerical simulations of different distribution network topologies (rural and urban networks) to identify the need and the cost of network reinforcement required to accommodate future load under various operating strategies, such as 'business as usual' (passive demand and passive network), against the smart grid approach. This led Pudjianto et al. to advocate the revision of network planning and design standards. Distribution network operators (DNOs), for example, would need to be incentivised to take advantage of smart control solutions as an alternative to strengthening the grid. In contrast, Baruah et al. (2014) emphasise here that the required level of uptake of heat pumps and EVs, as well as dramatic reductions in gas and oil consumption, as seen in the UK Infrastructure Transitions Research Consortium scenarios have major implications for both consumers and the existing national gas and oil infrastructure/industry in an electrification scenario. Baruah et al. highlight the fact that carefully planned transmission and distribution investments could provide the potential basis for 'no-regret' options. They could enable greater microgeneration uptake and exploitation of geographically distributed renewable resources. But energy system impacts of the magnitude identified by Baruah et al. (2014) could be further exaggerated over the longer-term by uncertainties regarding energy consumption linked to socio-economic growth, which their sensitivity analysis found to be significant.

The last of the end-use energy demand sectors (see again Figure 1) considered in this themed issue is industry. The industrial sector in the UK accounts for some $21 \%$ of total delivered energy and $29 \%$ of carbon dioxide emissions. It is very diverse in terms of manufacturing processes, ranging from highly energy-intensive steel production and petrochemicals processing to low-energy electronics fabrication (Dyer et al., 
Editorial: Progress in energy demand reduction - from here to 2050

Hammond
2008). The former typically employs large quantities of (often high-temperature) process energy, whereas the latter tends to be dominated by energy uses associated with space heating. Around 350 separate combinations of sub-sectors, devices and technologies can be identified (Dyer et al., 2008); each combination offers quite different prospects for energy efficiency improvements and carbon dioxide reductions, which are strongly dependent on the specific technological applications. Some element of sectoral aggregation is therefore inevitable in order to yield policy-relevant insights. In addition, this large variation across industry does not facilitate a cross-cutting, 'one size fits all' approach to the adaptation of new technologies in order to reduce energy demand, but, rather, requires tailored solutions for separate industries (Dyer et al., 2008). Thus, it is widely recognised that data on industrial energy use and the potential for GHG emissions reduction are arguably weakest in respect to this UK end-use demand sector. Consequently, UKERC recently commissioned research aimed at providing better information in support of the industrial modelling needs of UK policy makers, including the potential impact of fuel switching, particularly to potentially low carbon energy carriers, notably electricity, as well as the identification of difficult sectors/processes and areas where investment could be targeted most effectively. This has resulted in the development of an industrial usable energy database (UED) by Griffin et al. (2013a, 2013b); the beta version of which can be interrogated by way of the UKERC Energy Data Centre, in terms of the background documentation (Griffin et al., 2013a) and spreadsheet data (Griffin et al., 2013b). Bottom-up studies were undertaken for 'Iron and steel making', 'Chemicals processing', 'Cement manufacture', the 'Food and drink sector', and 'Paper production'. Together they account for about $65 \%$ of carbon dioxide equivalent $\left(\mathrm{CO}_{2 \mathrm{e}}\right)$ from UK industry. The approach and challenges to a UKERC-supported study of each of these subsectors were often unique. However, the general approach taken to each subsector was to identify the 2010 baseline energy use and GHG emissions, and then to determine the improvement potential offered through the application of best available technologies against this baseline. A top-down view of industry was also taken in order to evaluate how the modelled subsectors fit within industry as a whole. Finally, cross-cutting technologies that might offer improvement potential, but were not specific to a subsector of industry, were examined. Certain behavioural or good-practice measures are suitable for adoption across the board precisely because of their explicit independence from the type of technology employed (see, for example, Dyer et al. (2008)). Cost information is not explicitly included in the UED (Griffin et al., 2013a, 2013b), but the technical information can be utilised by cost-optimal, whole systems, energy-economic models, such as UK Times.

The GHG emissions from the UK industrial sector are illustrated in the pie chart presented as Figure 5 (Dr

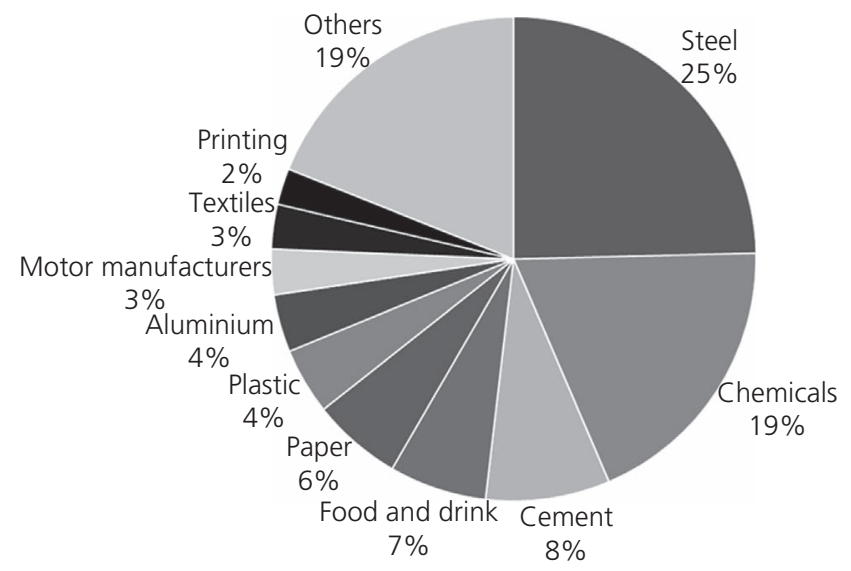

Figure 5. 'Greenhouse gas' emissions from the UK industrial sector: 2007 baseline. (source: Dr Jonathan B. Norman (University of Bath); based on data from DECC $(2009,2010,2012)$ and Defra (2012))

Jonathan B. Norman, University of Bath, private communication, 2014). This includes emissions from direct energy use, electricity use (indirect emissions) and industrial processes. In total, $31 \cdot 2$ million tonnes of $\mathrm{CO}_{2 \mathrm{e}}$ emissions $\left(\mathrm{MtCO}_{2 \mathrm{e}}\right)$ are represented in the pie chart. Energy use data were taken from UK government sources (DECC, 2009), and converted using relevant emissions factors (Defra, 2012). Process emissions are taken from Department of Energy and Climate Change (DECC) figures (DECC, 2010). The sub-sectors are based on industrial groupings employed for the purposes of establishing climate change agreements (CCAs), manipulating the data, which are mainly supplied in line with standard industrial classification (SIC) codes for UK economic activities, to best represent these groupings. An adjustment was also made to include blast furnace energy use in the representation of the steel sector, as this is not included in the figures reported by DECC (2009). Supplementary data were taken from the annual Digest of United Kingdom Energy Statistics ('Dukes') (DECC, 2012). In this themed issue, papers are presented that deal with two industrial sub-sectors: the cement sector (Griffin et al., 2014) and food and drink (Tassou et al., 2014). They account for some $8 \%$ and $7 \%$ respectively of UK industrial process GHG emissions (Figure 5), and are adopted here as being representative of the energy-intensive and non-energy-intensive segments of industry respectively (Hammond and Norman, 2012). A fuller picture of the UK industrial sector can be obtained by way of the UKERC industrial UED (Griffin et al., 2013a, 2013b).

The UK cement sector was responsible for around $7 \mathrm{MtCO}_{2 \mathrm{e}}$ in 2010 (Griffin et al., 2014). These emissions can be attributed to direct fuel use, the chemical reactions that occur as part of the 
Editorial: Progress in energy

demand reduction - from here

to $\mathbf{2 0 5 0}$

Hammond production process and electricity use (leading to indirect emissions). Historical trends show that the sector has made reductions in its emissions per unit of cement over the past two decades, through clinker substitution, fuel switching and efficiency improvements. This has largely been driven by energy costs and policy. However, there are engineering opportunities to use less cement while providing the same structural service in the construction sector; as recommended, for example, by Allwood and Cullen (2011). Much greater reductions in specific emissions out to 2050 would be required to meet GHG emissions reduction targets. Griffin et al. (2014) suggest that this will require more radical interventions, such as the adoption of CCS technology and alternative (low carbon) cement formulations. These options are presently unproven on a large scale, and would necessitate considerable support from both the industry and government policy to be realised. In fact, there is currently only a single kiln (inland at Rugby) that meets the practical throughput requirement of $\sim 4000-5000 \mathrm{t} / \mathrm{d}$. Indeed, it is far more likely that CCS 'hubs' will be centred adjacent to suitable gas pipelines and potential offshore storage reservoirs in the North or Irish Seas. The work of Griffin et al. (2014) formed part of, and draws on the results obtained from, the UKERC-funded 'Industrial energy use from a bottom-up perspective' consortium project and the consequent development of the UKERC industrial UED (Griffin et al., 2013a, 2013b). The prospects for reductions in the specific energy use and emissions associated with the UK cement industry have been explored under a range of four scenarios out to 2050: characterised as 'Low action', 'Reasonable action', 'Reasonable action including CCS' and 'Radical transition'. Griffin et al. (2014) note that historic trends, and those expected through technological innovation indicated by these scenario projections, suggest decreasing advances being made through efficiency improvements. This is characteristic of 'energy-intensive' manufacturing (Hammond and Norman, 2012), where high energy prices (Griffin et al. (2014) observe that energy costs typically represent $40 \%$ of operational costs for a cement manufacturer) have driven 'quick wins'. There is, according to Griffin et al. (2014), some potential for further contributions from clinker substitution and fuel switching, although such options are not without their difficulties. Clinker substitution could continue to increase somewhat without adversely affecting the properties of cement (up to a maximum of $40 \%$, from the current level of $\sim 30 \%$ (Griffin et al., 2014)). The main clinker substitutes in the UK rely on carbon dioxide intensive industries, blast furnaces and coal-fuelled electricity generation. Such operations may not be viable over the long term, when the national focus could well be on 'decarbonisation', and this could influence the economic availability of clinker substitutes. Cement kilns are well suited for the use of refuse-derived fuel (RDF), or solid recovered fuel/specified recovered fuel (SRF), as the mineral content in such fuels is incorporated into the clinker without residual ash or heavy metal disposal being required. More broadly, ordinary Portland cement (OPC) is well established, having a mature supply chain and being well understood for use in construction. Griffin et al. (2014) therefore believe that the OPC industry in Britain is likely to take incremental steps in the long term to ensure its continued existence, with the aim of supplying well-tested, familiar products to the construction industry. Nevertheless, the successful adoption of alternative cements outside the UK might act as an appropriate driver for change in this country.

Tassou et al. (2014) provide a valuable summary of energy demand over the whole food supply chain (FSC): across agriculture, food processing, retailing, domestic preparation and food disposal. This state-of-the-art review examines the technological opportunities for reducing energy consumption, and brings together a substantial amount of information from multiple and very practical sources. It notes that the FSC is responsible for approximately $18 \%$ of total UK energy use, $176 \mathrm{MtCO}_{2 \mathrm{e}}$ emissions, and $15 \mathrm{Mt}$ of food waste. They therefore examine the literature on energy consumption and emissions from each part of the food chain, as well as outlining approaches for demand reduction that appear promising. It yields a basis for further refinement of the FSC energy demand estimates and the development of improved methodologies to stimulate reductions in energy and resource use within the RCUK Centre for Sustainable Energy Use in Food Chains (as part of the RCUK 'End use energy demand' initiative). In agriculture, even though energy use is moderate compared to the other parts of the whole FSC, Tassou et al. contend that energy savings of up to $20 \%$ can be achieved through renewable energy generation and the use of more efficient technologies and smart control systems. In fact, the sustainable intensification of agriculture and field operations, not explicitly discussed in this piece, has a huge potential to reduce energy demand across the FSC. In food processing, they argue that energy can be saved at the processing plant level by optimising and integrating processes and systems to reduce energy intensity, for example, through better process control, advanced sensors and equipment for on-line measurement, and intelligent adaptive control of key parameters. Likewise, they propose the minimisation of waste through energy recovery and better use of by-products. These findings are similar to those from the UKERC-funded industrial energy use study (Griffin et al., 2013a, 2013b) that examined the 'Food and drink sector' in terms of improvement potential from heat pumps, energy management and heat recovery, and other cross-cutting measures (such as motor and boiler systems). Tassou et al. (2014) note that, in the food retail sector, significant progress in energy efficiency has been made in recent years, but that there still exist potential improvements in the efficiency of refrigeration systems, 'heating, ventilation and air conditioning' (HVAC) and refrigeration system integration, 
Energy

Volume 167 Issue EN3
Editorial: Progress in energy

demand reduction - from here

to 2050

Hammond heat recovery and amplification (again analogous to that suggested by Griffin et al. (2013a, 2013b)) using heat pumps, DSP, system diagnostics, and local CHP generation and trigeneration. Tassou et al. also identify energy-saving opportunities from the use of low-energy lighting systems, improved thermal insulation of the building fabric, integration of renewable energy sources, and thermal energy storage systems. They observe that energy consumption in catering facilities is primarily the result of cooking and baking, refrigeration and HVAC systems. Here energy demand reduction can be achieved from the use of more efficient equipment, as well as by way of behavioural changes with respect to type of food consumed, food preparation practices and environmental conditions in the premises. In terms of home energy savings, they note that food consumption is affected by many factors, including food availability, disposable income, urbanisation, marketing, religion, culture and consumer attitudes. Inevitably there is further work to be done in this complex area. Changes in energy/resource use in one part of the supply chain can impact in other parts, for example, because of the interconnectedness of the FSC. Thus, better demand forecasting by retailers could impact on resource use in agriculture and food waste reduction in the FSC overall (Parfitt et al., 2010). Nevertheless, Tassou et al. (2014) believe that significant energy savings can be achieved from the use of more efficient appliances and food preparation methods (such as microwave technology rather than oven cooking), as well as changes in consumer diets and behaviour. They contend that all these factors should be taken into account in devising new approaches and technologies to effect reductions in energy demand and resource use along the whole food chain.

In the final paper within this themed issue, Hannon and Skea (2014) draw on the findings of a series of 'expert' workshops organised by the RCUK Energy Strategy Fellowship (awarded to Skea), and held during the process of developing the Fellowship team's UK energy research and training needs prospectus (Skea et al., 2013). Priority themes and topics for energy demand research are identified in the household, commercial, industrial and transport sectors: in line with those in the simplified model of UK energy flows illustrated in Figure 1 (Hammond, 2000) and the corresponding electricity demand projections arising from the UK transition pathways depicted in Figures 2-4 (Barton et al., 2013a). The priority themes identified by Hannon and Skea include system-level and socio-technical perspectives on energy demand, and energy use in non-domestic buildings. They note that the nondomestic sector is more heterogeneous (see also Dyer et al. (2008) and similar remarks in relation to industrial energy demand and emissions reduction above) and consequently presents a more challenging area. Hannon and Skea (2014) underline the importance of incremental and radical technological innovation. They argue that there is a need to conduct research into opportunities for demand reductions achieved through large-scale energy initiatives, such as infrastructure change and spatial planning, to complement research into applications at smaller scales, such as building design or appliances. In addition, they highlight the need to support 'research, development and demonstration' (RD\&D) that is sensitive to what they regard as the 'systemic nature' of energy demand, involving reduction strategies at different levels: the individual, household, city and the sector as a whole. Hannon and Skea emphasise the importance of both technological and non-technological (or 'socio-technical') innovations. In respect to the latter, they believe that strategic spatial planning at the regional and national level could help to reduce energy demand by facilitating the use of public transport and alternative transport modes (e.g. cycling, walking, etc.). It could help to optimise the effectiveness of all forms of transport by reducing congestion and moderating traffic speeds. Likewise, careful town planning can obviate the need to travel by locating new homes close to workplaces and essential services. In industry, Hannon and Skea (2014) assert that the development of lowenergy industrial processes (relying on novel manufacturing technologies, industrial catalysts and materials) depends on how they are configured and managed as part of an integrated, energy-efficient production chain. They argue that, in order to secure the desired reductions, there is a need for 'interdisciplinary research; field trials; arrangements for data collection, curation and sharing; and raising funding support to levels comparable with those for energy supply technologies'. Energy demand is shaped by a myriad of factors stemming from different system dimensions (such as technologies, institutions and user or 'social' practices). Thus, in order to help maximise the quality and impact, they believe that interdisciplinary research is essential. Hannon and Skea recognise that the analysis of energy flows has been hindered in several cases by an inadequate level of disaggregation within UK official statistical sources. They argue that extensive field trials are therefore needed to assess how demand-side interventions perform in 'real-world' settings. Data from such trials should then be made available to researchers for secondary analysis. All this, the authors believe, could be facilitated by the establishment of more stringent data sharing policies and the support of infrastructure for data collection and curation. Finally, Hannon and Skea (2014) recommend that financial support for energy demand-side research should be brought into line with that for research on the supply side. Both approaches will play a key role in helping the UK to meet its climate change, energy security and economic goals, but have long been out of balance.

A robust transitional energy strategy is clearly required if the UK is going to achieve its challenging GHG emissions target for 2050, as well as more generally in the industrialised world. An important focus will arguably need to be on energy demand 
Editorial: Progress in energy

demand reduction - from here

to $\mathbf{2 0 5 0}$

Hammond reduction and energy efficiency improvements (a move in the direction of 'Factor 4' or more resource-efficient technologies; the scale of which are depicted by the IPAT or 'sustainability' Equation 1 (Holdren and Ehrlich, 1974; Jacobs, 1996) and in Table 1 (Hammond, 2004; Meadows et al., 1992)) and significantly minimising GHG emissions. The elements of such a strategy will change over time, and the 'optimal' mix of sociotechnical measures at any given instant will be uncertain when viewed from the present. Various medium-term options for energy demand reduction in the UK have been described in this themed issue, across the different end-use sectors (Figure 1): the built environment, transport and industry. For a country like Britain with an only slowly rising population size, environmental protection could be sustained with modest economic growth provided the energy intensity and pollutant/energy ratio both fall. This has been achieved to some degree over recent decades (Hammond, 2000). Balancing economic growth in terms of traditional GDP per capita with measures for social and environmental improvement would result in an upward trend in indices of 'real' human development. The present themed issue of Energy has primarily focused on energy-related considerations here in the UK. It is certainly important that developed countries of the 'North' play their full part in maintaining environmental sustainability, as they currently emit the bulk of pollutants into the atmosphere. But sustainable development must also be viewed in a global context. The task facing the nearly $80 \%$ of the world population that live in developing countries of the 'South' is daunting. They have, in most cases, rapidly growing populations, which will drive up energy consumption and environmental pollution. This will feed back to the whole planet, and thereby alter the climate in the wealthier nations. Consequently, they need assistance from industrial countries to promote economic growth in less developed countries (which will, in time, induce a 'demographic transition') and improve their energy systems. Economic development would benefit from, perhaps even require, fairer terms of trade between the member countries of the Organisation for Economic Cooperation and Development (OECD) and developing nations. Environmental sustainability could be aided by the transfer of best-practice energy technologies from the richer to poorer regions. This will ultimately be in the interests of all the citizens of 'spaceship Earth' (Hammond, 2000, 2004).

\section{Acknowledgements}

Research by the 'themed issue champion' (GPH) on the technology assessment of energy systems and transition pathways to a low carbon dioxide future is part of a programme at the University of Bath that is supported by a series of research grants and contracts awarded by various bodies associated with the RCUK Energy Programme. During the preparation of this piece, he jointly led a large consortium of nine university partners (Bath, Cardiff, East Anglia, Leeds, Loughborough, Strathclyde and Surrey, as well as Imperial College London and University College London) funded by the EPSRC entitled 'Realising transition pathways: Whole systems analysis for a UK more electric low carbon energy future' (under grant EP/ K005316/1). He also led a small consortium of three university partners (Bath, Oxford and University College London) studying 'Industrial energy use from a bottom-up perspective' funded by the UK Energy Research Centre (under the Phase 2 grant NE/G007748/1). Finally, he is presently a co-investigator of the EPSRC 'UK INDEMAND' End-use Energy Demand Centre (under grant EP/K011774/1); this is a national research centre made up of four university partners (Bath, Cambridge, Leeds and Nottingham Trent) studying the potential for reducing industrial energy and material use in supplying UK needs. The author is grateful for the interaction with other members of these consortia, made up of participants from many UK universities. However, the views expressed here are those of the author alone and do not necessarily reflect the views of the collaborators or the policies of the funding bodies.

\section{REFERENCES}

Allwood JM and Cullen JM (2011) Sustainable Materials - With Both Eyes Open. UIT Cambridge Ltd, Cambridge, UK.

Barton J, Davies L, Dooley B et al. (2013a) Transition Pathways for a UK Low Carbon Electricity System: Comparing Scenarios and Technology Implications. EPSRC 'Realising Transition Pathways' Consortium Project Working Paper 2013/5. See http://www.realisingtransitionpathways.org.uk/ (accessed 09/09/2014).

Barton J, Huang S, Infield D et al. (2013b) The evolution of electricity demand and the role for demand side participation, in buildings and transport. Energy Policy 52: 85-102.

Baruah P, Eyre N, Qadrdan M et al. (2014) Energy system impacts from heat and transport electrification. Proceedings of the Institution of Civil Engineers - Energy 167(3): 139-151.

Bolton R and Foxon TJ (2011) Governing infrastructure networks for a low carbon economy: co-evolution of technologies and institutions in UK electricity distribution networks. Competition and Regulation in Network Industries 12(1): 2-27.

Brand C, Tran M and Anable J (2012) The UK transport carbon model: An integrated life cycle approach to explore low carbon futures. Energy Policy 41: 107-124.

Brown Al, Hammond GP, Jones Cl and Rogers FJ (2009) Greening the UK building stock: historic trends and low carbon futures 1970-2050. Transactions of the Canadian Society of Mechanical Engineering 33(1): 89-104.

Climate Change Act 2008 (2008) Elizabeth II. Chapter 27.

The Stationery Office, London, UK.

See http://www.legislation.gov.uk/ukpga/2008/27/pdfs/ ukpga_20080027_en.pdf (accessed 09/09/2014).

DECC (Department for Energy and Climate Change) (2009) 
Editorial: Progress in energy demand reduction - from here to 2050

Hammond
Table 4.6: Detailed industrial energy consumption by fuel 1995-2007. In Energy Consumption in the UK (ECUK). DECC, London, UK, Spreadsheet.

DECC (2010) UK Greenhouse Gas Emissions - Final Figures. Office of National Statistics (ONS) Statistical Release, Newport, 25 March 2010. DECC, London, UK.

DECC (2012) Digest of United Kingdom Energy Statistics 2012. The Stationery Office, London, UK.

Defra (Department for Environment, Food and Rural Affairs) (2012) 2012 Guidelines to DefralDECC's GHG Conversion Factors for Company Reporting. Defra, London, UK, Spreadsheet.

Dijk M and Yarime M (2010) The emergence of hybrid-electric cars: innovation path creation through co-evolution of supply and demand. Technological Forecasting and Social Change 77(8): 1371-1390.

Dijk M, Orsato RJ and Kemp R (2013) The emergence of an electric mobility trajectory. Energy Policy 52: 135-145.

DTI (Department of Trade and Industry) (2007) Meeting the Challenge - A White Paper on Energy. The Stationery Office, London, UK.

Dyer CH, Hammond GP, Jones $\mathrm{Cl}$ and McKenna RC (2008) Enabling technologies for industrial energy demand management. Energy Policy 36(12): $4434-4443$.

Foxon TJ, Hammond GP and Pearson PJG (2010) Developing transition pathways for a low carbon electricity system in the UK. Technological Forecasting and Social Change 77(8): 1203-1213.

Geels FW (2002) Technological transitions as evolutionary reconfiguration processes: a multi-level perspective and a case-study. Research Policy 31(8-9): 1257-1274.

Griffin P, Hammond G and Norman J (2013a) Industrial Energy Use from a Bottom-Up Perspective: Developing the Usable Energy Database (Beta Version). UK Energy Research Centre, London, UK, Report UKERC/WP/ED/2013/002. See http://data.ukedc.rl.ac.uk/cgi-bin/dataset_catalogue// view.cgi.py?id=15 (accessed 09/09/2014).

Griffin P, Hammond G and Norman J (2013b) Industrial Energy Use from a Bottom-Up Perspective: Usable Energy Database (Spreadsheet - Beta Version). UK Energy Research Centre, London, UK. See http://data.ukedc.rl.ac. uk/cgi-bin/dataset_catalogue//view.cgi.py?id=15 (accessed 09/09/2014).

Griffin PW, Hammond GP and Norman JB (2014) Prospects for emissions reduction in the UK cement sector. Proceedings of the Institution of Civil Engineers - Energy 167(3): 152-161.

Hall JW, Henriques JJ, Hickford AJ and Nicholls RJ (2013) Systems-of-systems analysis of national infrastructure. Proceedings of the Institution of Civil Engineers Engineering Sustainability 166(5): 249-257.

Hammond GP (2000) Energy, environment and sustainable development: a UK perspective. Transactions of the Institution of Chemical Engineers, Part B: Process Safety and Environmental Protection 78(4): 304-323.
Hammond GP (2004) Towards sustainability: energy efficiency, thermodynamic analysis, and the 'two cultures'. Energy Policy 32(16): 1789-1798.

Hammond GP and Jones Cl (2008) Embodied energy and carbon in construction materials. Proceedings of the Institution of Civil Engineers - Energy 161(2): 87-98.

Hammond G and Jones C (2011) Embodied Carbon: The Inventory of Carbon and Energy (ICE). BSRIA Ltd, Bracknell, UK, BSRIA Guide BG 10/2011 (Lowrie F and Tse $\mathrm{P}$ (guide series eds)).

Hammond GP and Norman JB (2012) Decomposition analysis of energy-related carbon emissions from UK manufacturing. Energy 41(1): 220-227.

Hammond GP and Pearson PJG (2013) Challenges of the transition to a low carbon, more electric future: From here to 2050 (Editorial). Energy Policy 52: 1-9.

Hannon M and Skea J (2014) UK innovation support for energy demand reduction. Proceedings of the Institution of Civil Engineers - Energy 167(3): 171-180.

Herring H (1999) Does energy efficiency save energy? The debate and its consequences. Applied Energy 63(3): 209-226.

Holdren JP and Ehrlich PR (1974) Human population and the global environment. American Scientist 62(3): 282-292.

Jacobs M (1996) The Politics of the Real World. Earthscan, London, UK.

Killip G, Fawcett T and Janda KB (2014) Innovation in low-energy home renovation in the UK and France. Proceedings of the Institution of Civil Engineers - Energy 167(3): 117-124.

Meadows DH, Meadows DL and Randers J (1992) Beyond the Limits. Earthscan, London, UK.

Meijer IS, Hekkert MP, Faber J and Smits RE (2006) Perceived uncertainties regarding socio-technological transformations: towards a framework. International Journal of Foresight and Innovation Policy 2(2): 214-240.

Morton C, Anable J and Brand C (2014) Policy making under uncertainty in electric vehicle demand. Proceedings of the Institution of Civil Engineers - Energy 167(3): 125-138.

Parfitt J, Barthel M and Macnaughton S (2010) Food waste within food supply chains: quantification and potential for change to 2050. Philosophical Transactions of the Royal Society B 365(1554): 3065-3081.

Pelenur MJ and Cruickshank HJ (2012) Closing the energy efficiency gap: A study linking demographics with barriers to adopting energy efficiency measures in the home. Energy 47(1): 348-357.

Pelenur M and Cruickshank H (2014) Motivations to adopting energy efficiency measures in the home. Proceedings of the Institution of Civil Engineers - Energy 167(3): 103-116.

Post (Parliamentary Office of Science and Technology) (2012) Energy Use Behaviour Change. Post, London, UK, Postnote No. 417. 
Editorial: Progress in energy

demand reduction - from here

to $\mathbf{2 0 5 0}$

Hammond
Pudjianto D, Djapic P, Aunedi M et al. (2013) Smart control for minimizing distribution network reinforcement cost due to electrification. Energy Policy 52: 76-84.

Rip A and Kemp R (1998) Technological change. In Human Choices and Climate Change: Vol. 2: Resources and Technology (Rayner S and Malone EL (eds)). Battelle Press, Columbus, OH, USA, pp. 327-399.

Rosenow J and Eyre N (2013) The Green Deal and the Energy Company Obligation. Proceedings of the Institution of Civil Engineers - Energy 166(3): 127-136.

Skea J, Hannon M and Rhodes A (2013) Investing in a Brighter Energy Future: Energy Research and Training Prospectus. Imperial College London, London, UK.

Slesser M (1978) Energy in the Economy. Macmillan, London, UK.

Tassou S, Kolokotroni M, Gawreesunker B and Stojceska V (2014)
Energy demand and reduction opportunities in the UK food chain. Proceedings of the Institution of Civil Engineers - Energy 167(3): 162-170.

Technology Foresight (1995) Progress Through Partnership 5: Transport. HMSO, London, UK.

von Weizsacker E, Lovins AB and Lovins LH (1997) Factor Four: Doubling Wealth, Halving Resource Use. Earthscan, London, UK.

von Weizsacker E, Hargroves KC, Smith $\mathrm{MH}$, Desha $\mathrm{C}$ and Stasinopoulos P (2009) Factor Five: Transforming the Global Economy through 80\% Improvements in Resource Productivity. Earthscan, London, UK.

Walker WE, Harremoës P, Rotmans J et al. (2003) Defining uncertainty: a conceptual basis for uncertainty management in model-based decision support. Integrated Assessment 4(1): 5-17. 